\title{
Fatty Acids and Autism Spectrum Disorders: The Rett Syndrome Conundrum
}

\author{
Claudio De Felice $^{1^{*}}$, Cinzia Signorini ${ }^{2 *}$, Silvia Leoncini ${ }^{2,3}$, Alessandra Pecorelli $^{2,3}$, Thierry Durand ${ }^{4}$, \\ Jean-Marie Galano ${ }^{4}$, Valérie Bultel-Poncé ${ }^{4}$, Alexandre Guy ${ }^{4}$, Camille Oger ${ }^{4}$, Gloria Zollo ${ }^{2,3}$, \\ Giuseppe Valacchi ${ }^{5,6}$, Lucia Ciccoli ${ }^{2}$, Joussef Hayek ${ }^{3}$
}

\begin{abstract}
${ }^{1}$ Neonatal Intensive Care Unit, University Hospital AOUS, Policlinico "S. M. Alle Scotte", Siena, Italy; ${ }^{2}$ Department of Molecular and Developmental Medicine, University of Siena, Siena, Italy; ${ }^{3}$ Child Neuropsychiatry Unit, University Hospital AOUS, Policlinico "S. M. Alle Scotte", Siena, Italy; ${ }^{4}$ Institut des Biomolécules Max Mousseron (IBMM), Montpellier, France; ${ }^{5}$ Department of Life Science and Biotechnologies, University of Ferrara, Ferrara, Italy; ${ }^{6}$ Department of Food and Nutrition, Kyung Hee University, Seoul, South Korea.
\end{abstract}

Email: "geniente@gmail.com, *cinzia.signorini@unisi.it

Received July $2^{\text {nd }}, 2013$; revised August $2^{\text {nd }}, 2013$; accepted August $9^{\text {th }}, 2013$

Copyright (C) 2013 Claudio De Felice et al. This is an open access article distributed under the Creative Commons Attribution License, which permits unrestricted use, distribution, and reproduction in any medium, provided the original work is properly cited.

\begin{abstract}
Autism spectrum disorders (ASDs) are epidemically explosive clinical entities, but their pathogenesis is still unclear and a definitive cure does not yet exist. Rett syndrome (RTT) is a rare genetically determined cause of autism linked to mutations in the X-linked $M e C P 2$ gene or, more rarely, in $C D K L 5$ or FOXG1. A wide phenotypical heterogeneity is a known feature of the disease. Although several studies have focused on the molecular genetics and possible protein changes at different levels, to date very little attention has been paid to fatty acids in this disease, which could be considered as a natural paradigm for the ASDs. To this regard, a quite enigmatic feature of the disease is the evidence in the affected patients of an extensive peroxidation of polyunsaturated fatty acids (arachidonic acid, AA, docosaexahenoic acid, DHA, adrenic acid, AdA and, to a lesser extent, eicosapentaenoic acid, EPA), in contrast with amelioration of the redox changes and phenotypical severity following the supplementation of some of those same fatty acids (DHA + EPA). Therefore, fatty acids may represent a kind of Janus Bifrons in the particular context of RTT. Here, we propose a rational explanation for this apparent "fatty acid paradox" in RTT. A better understanding of this paradox could also be of help to get a better insight into the complex mechanism of action for polyunsaturated fatty acids in health and disease.
\end{abstract}

Keywords: Fatty Acids; Arachidonic Acid; Docosahexaenoic Acid; Adrenic Acid; Eicosapentaenoic Acid; Rett Syndrome; Autism Spectrum Disorders

\section{Background}

Polyunsaturated Fatty Acids (PUFAs) are becoming a hot topic in the research for neurodevelopmental and neuropsychiatric disorders [1-3]. Speaking about developmental disorders, such as Autism Spectrum Disorders (ASD) the current scientific thinking is mainly focused on genetic and/or neurologic approaches. However, for these conditions the cellular approach, which stresses what is ubiquitous and essential for cell function, seems far too often to be neglected. In this sense, PUFAs are really ubiquitous and essential components of cell membranes, where the majority of the cell machinery for intra- and

${ }^{*}$ Corresponding authors. inter-cellular communications (i.e., involving signalling and transduction) resides and controls the intracellular environment integrity. In particular, within the nervous tissue, PUFAs influence neurogenesis and neurotransmission as their metabolites modulate immune and inflammatory processes, as well as oxidative stress (OS).

\section{Rett Syndrome: A Unique Natural Model of Neuroregressive Disorders}

In recent years, our group has deeply explored the link between PUFAs and Rett syndrome (RTT), an X-linked dominant neurodevelopmental disorder that predominantly affects females with an incidence of one in 10,000 - 15,000 female births [4,5]. Affected patients manifest 
various neuro-psychiatric features, including autistic traits, epileptic seizures, gait ataxia, stereotypies and loss of finalistic hands use [4]. Mutation of the MECP2 gene accounts for approximately $90 \%$ of cases with classic RTT [6]. Besides the classic or typical presentation, atypical RTT phenotypes have been identified, including the "so-called" preserved speech variant (usually associated with $M E C P 2$ mutations), early seizure (often related to cyclin-dependent kinase-like 5, CDKL5, gene mutations) and the congenital variant (often linked to Forkhead box G1, FOXG1, gene mutations) [7].

To date, the biological mechanisms linking the gene mutation to the phenotypic expression of the disease, including its wide heterogeneity, are yet to be clarified. However, recent discoveries, mainly by our team, concerning the emerging role of alteration of the redox homeostasis offer an alternative explanation which is not mutually exclusive with others previously proposed.

From our perspective, RTT represents a unique model of chronic oxidative stress with autistic features that are clearly linked to a gene mutation in which de novo sporadic mutations of the $M E C P 2$ accounts for the great majority of the causes. Nevertheless RTT also represents a complex and fascinating field of research as cumulating evidence points out that it is not a simple monogenic disease [8] as epigenetic mechanisms clearly play a role [9]. A valuable feature of the disease is the availability of several different experimental models, where the spearhead is represented by the reversibility models $[10,11]$ that offers a unique resource for testing possible causeeffect relationships for several neuro-regressive human disorders, also of higher social impact.

\section{Lipid Metabolism in RTT}

Several lipid abnormalities in brain tissue and blood are reported in RTT. Altered lipid and ganglioside patterns in cerebrum, cerebellum, and cerebrospinal fluid of patients have been described [12-14]. Some of these brain lipid changes are associated with neuropathological alterations, including loss of Purkinje cells, atrophy, synaptic and myelin abnormalities in frontal cortex [12-15]. Decreased serum levels of very long-chain fatty acids (VLCFA) and carnitine have also been evidenced in RTT patients $[16,17]$. It can be speculated that low carnitine levels impede transportation to mitochondria, thus inhibiting the oxidation of long-, medium- and short-chain fatty acids, which is to a certain extent compensated by intensified $\beta$-oxidation of VLCFA in the peroxisomal system [16].

Interestingly, circulating levels of two adipocytokines (leptin and adiponectin) are also found to be increased in RTT patients, as compared to those of healthy controls $[18,19]$. Growth failure is a common feature of RTT pa- tients and many individuals show clinical signs of moderate to severe malnutrition [20]. Moreover, increased plasma levels of leptin are detectable in RTT patients, but they are unrelated to the body mass index, thus suggesting that leptin might participate to clinical manifestations of the disease other than weight balance and adiposity [18]. Indeed, both adipocytokines could act, in either synergic or antagonistic ways, in several metabolic and immunological processes [21].

More recently, our group has shown that RTT patients have an altered plasma lipid profile with high levels of high density lipoproteins (HDL) and low density lipoproteins (LDL), as a possible consequence of an oxidative posttranslational mechanism in the Scavenger Receptor B1(SRB1) which mediates the selective uptake of cholesteryl esters from HDL as well as LDL into the cells without internalizing lipoprotein particles [20]. In particular, decreased SRB1 levels in RTT skin fibroblasts cultures have been demonstrated to be the consequence of its binding with 4-hydroxy-2-nonenal (4HNE), a product of lipid peroxidation, and of its increased ubiquitination [22]. Therefore, the link between lipids and OS in RTT appears to be far more complex than previously thought.

\section{The "Fatty Acids Paradox" in RTT}

Biochemical evidence of an extensive PUFAs peroxidation (arachidonic acid, AA, docosahexaenoic acid, DHA, adrenic acid, AdA and, to a lesser extent, eicosapentaenoic acid, EPA) is present in the affected patients. Indeed, abnormal plasma levels of lipid peroxidation end-products $\left[\mathrm{F}_{2}\right.$-isoprostanes $\left(\mathrm{F}_{2}\right.$-IsoPs $), \mathrm{F}_{4}$-neuroprostanes ( $\mathrm{F}_{4}$-NeuroPs), and $\mathrm{F}_{2}$-dihomo-isoprostanes $\left(\mathrm{F}_{2}\right.$ dihomo-IsoPs)] have been detected in RTT, whose precursor fatty acids are AA, DHA and AdA, respectively [8,23-29].

A quite enigmatic feature of the disease is that exogenous administration of $\omega-3$ PUFAs (DHA + EPA), at disease stages I-IV, has been shown to moderately reduce clinical severity and significantly reduce the levels of IsoPs and 4-HNE PAs in RTT patients [30]. Thus, contrary to expectations, the assumed fatty acids are not further oxidized, while the actual endogenous IsoPs production is reduced (the "fatty acid paradox") together with amelioration of the clinical disease severity.

Conceivably, an excess of peroxidation end products from $\omega-6$ and $\omega-3$ PUFAs would actually imply an excessive consumption of these PUFAs in the cell membranes, thus paving the way for a new perspective on the nutritional horizons in RTT.

This observation generates an interesting concept according to which the increased isoprostanes levels in RTT are not simply the effect of the peroxidation of the 
PUFA precursors following the attack by radical oxygen species (ROS), but rather the effect of a potential dysregulation of the molecular targets of $\omega-3$ PUFAs, including ionic channels and/or eicosanoids biosynthesis. In addition, it is still unclear whether the action of $\omega-3$ PUFAs is a direct one or it is, more likely, mediated by secondary metabolites [31-33]. As RTT girls appear to chronically suffer from oxidation of PUFAs, either $\omega-3$ (i.e., DHA/EPA) or $\omega-6$ (i.e., AA, AdA), but, at the same time, benefit from $\omega$-3 PUFAs supplementation, it can be inferred that these patients would need an $\omega-3$ PUFAs replacement as a consequence of a persistent PUFAs oxidation within the chronic OS context. On the other hand, it is also possible that, in RTT, the endogenous PUFAs are, for their own nature, more susceptible to the OS as compared to the exogenous ones. Therefore, administered PUFAs may be seen as counteracting this intrinsic defect. Interestingly, impaired cholesterol metabolism has been very recently demonstrated in a Mecp2-null mouse model of RTT, with statin treatment leading to improvement of motor symptoms and conferring increased longevity [34]. This report appears to be in agreement with our prior observation regarding an unexplained hypercholesterolemia in RTT patients [22] and with our prior inferences on a possible use of statins in RTT as derived by comparison of full exome sequences in two special pairs of RTT sisters harbouring the same $\mathrm{MeCP} 2$ mutation and discordant clinical phenotype [8]. Notably, $\omega-3$ PUFAs have been widely used, either alone or in combination with pharmacological molecules, as lipid lowering agents in hypercholesterolemia, with consistently fewer side effects as compared to those reported for statins [35]

Overall, the lipid metabolism in RTT appears to be a surprisingly fruitful field of research to be explored in the coming years.

\section{Conclusion}

Surprisingly, the use of exogenous fatty acids ( $\omega-3$ PUFAs), as dietary supplementation, and the concomitant identification of their peroxidation end-products have unveiled a previously unrecognized feature of RTT, which we would like to define as the "fatty acid paradox" of the disease. Our interpretation, at this time, is that these fatty acids may represent a molecular target for the disease, so far thought to be simply a primary genetically determined developmental disorder of the brain. Rather, RTT should be perhaps considered as a developmental brain disease consequent to a complex lipid metabolism disorder in a pro-oxidant shifted redox imbalance context.

\section{Acknowledgements}

We sincerely thank the professional singer Matteo Setti (www.matteosetti.com) for having serendipitously triggered the scientific studies on hypoxia and oxidative stress in Rett girls and for his many charity concerts and continued interest in the scientific aspects of our research.

The present research project has been funded by the Tuscany Region [Bando Salute 2009, “Antioxidants ( $\omega$-3 Polyunsaturated Fatty Acids, lipoic acid) supplementation in Rett syndrome: A novel approach to therapy"], Italy. We are grateful to the Italian Health Ministry and Tuscany Region for the grant "Induced pluripotent stem cells as in vitro models for the study of Rett syndrome pathogenesis and identification of therapeutic targets" (team leader prof. Alessandra Renieri, University of Siena). We sincerely thank Drs. Pierluigi Tosi, Silvia Briani and Roberta Croci from the Administrative Direction of the Azienda Ospedaliera Senese for continued support to our studies and the Azienda Ospedaliera Senese for prior purchasing of the gas spectrometry instrumentation.

This research is dedicated to all the Rett girls and their families who represented the true inspiration for our research.

\section{REFERENCES}

[1] M. Zeman, R. Jirak, M. Vecka, J. Raboch and A. Zak, "n-3 Polyunsaturated Fatty Acids in Psychiatric Diseases: Mechanisms and Clinical Data," Neuro Endocrinology Letters, Vol. 33, No. 8, 2012, pp. 736-748.

[2] J. P. Schuchardt, M. Huss, M. Stauss-Grabo and A. Hahn, "Significance of Long-Chain Polyunsaturated Fatty Acids (PUFAs) for the Development and Behaviour of Children," European Journal of Pediatrics, Vol. 169, No. 2, 2010, pp. 149-164. doi:10.1007/s00431-009-1035-8

[3] P. L. Prior and J. C. Galduróz, "(n-3) Fatty Acids: Molecular Role and Clinical Uses in Psychiatric Disorders," Advances in Nutrition, Vol. 3, No. 3, 2012, pp. 257-265. doi:10.3945/an.111.001693

[4] B. Hagberg, J. Aicardi, K. Dias and O. Ramos, "A Progressive Syndrome of Autism, Dementia, Ataxia, and Loss of Purposeful Hand Use in Girls: Rett's Syndrome: Report of 35 Cases," Annals of Neurology, Vol. 14, No. 4, 1983, pp. 471-479. doi:10.1002/ana.410140412

[5] T. Bienvenu, C. Philippe, N. De Roux, M. Raynaud, J. P. Bonnefond, L. Pasquier, G. Lesca, J. Mancini, P. Jonveaux, A. Moncla, J. Feingold, J. Chelly and L. Villard, "The incidence of Rett Syndrome in France," Pediatric Neurology, Vol. 34, No. 5, 2006, pp. 372-375. doi:10.1016/j.pediatrneurol.2005.10.013

[6] H. Y. Zoghbi, "MeCP2 Dysfunction in Humans and Mice," Journal of Child Neurology, Vol. 20, No. 9, 2005, pp. 736-740. doi:10.1177/08830738050200090701

[7] J. L. Neul, W. E. Kaufmann, D. G. Glaze, J. Christodoulou, A. J. Clarke, N. Bahi-Buisson, H. Leonard, M. E. Bailey, N. C. Schanen, M. Zappella, A. Renieri, P. Hup- 
pke, A. K. Percy and Rett Search Consortium, "Rett Syndrome: Revised Diagnostic Criteria and Nomenclature," Annals of Neurology, Vol. 68, No. 6, 2010, pp. 944-950.

[8] E. Grillo, C. Lo Rizzo, L. Bianciardi, V. Bizzarri, M. Baldassarri, O. Spiga, S. Furini, C. De Felice, C. Signorini, S. Leoncini, A. Pecorelli, L. Ciccoli, M. A. Mencarelli, J. Hayek, I. Meloni, F. Ariani, F. Mari and A. Renieri, "Revealing the Complexity of a Monogenic Disease: Rett Syndrome Exome Sequencing," Public Library of Science One, Vol 8, No. 2, 2013, Article ID: e56599.

[9] K. Miyake, C. Yang, Y. Minakuchi, K. Ohori, M. Soutome, T. Hirasawa, Y. Kazuki, N. Adachi, S. Suzuki, M. Itoh, Y. I. Goto, T. Andoh, H. Kurosawa, M. Oshimura, M. Sasaki, A. Toyoda and T. Kubota, "Comparison of Genomic and Epigenomic Expression in Monozygotic Twins Discordant for Rett Syndrome," Public Library of Science One, Vol. 8, No. 6, 2013, Article ID: e66729.

[10] J. Guy, H. Cheval, J. Selfridge and A. Bird, "The Role of MeCP2 in the Brain," Annual Review of Cell and Developmental Biology, Vol. 27, 2011, pp. 631-652. doi:10.1146/annurev-cellbio-092910-154121

[11] J. Guy, J. Gan, J. Selfridge, S, Cobb and A. Bird, "Reversal of Neurological Defects in a Mouse Model of Rett Syndrome," Science, Vol. 315, No. 5815, 2007, pp. 11431147. doi:10.1126/science.1138389

[12] A. Lekman, B. Hagberg and L. Svennerholm, "Altered Cerebellar Ganglioside Pattern in Rett Syndrome," Neurochemistry International, Vol. 19, No. 4, 1991, pp. 505509. doi:10.1016/0197-0186(91)90068-O

[13] A. Y. Lekman, B. A. Hagberg and L. T. Svennerholm, "Membrane Cerebral Lipids in Rett Syndrome," Pediatric Neurology, Vol. 7, No. 3, 1991, pp. 186-190. doi:10.1016/0887-8994(91)90082-V

[14] A. Y. Lekman, B. A. Hagberg and L. T. Svennerholm, "Cerebrospinal Fluid Gangliosides in Patients with Rett Syndrome and Infantile Neuronal Ceroid Lipofuscinosis," European Journal of Paediatric Neurology, Vol. 3, No. 3, 1999, pp. 119-123. doi:10.1016/S1090-3798(99)90099-5

[15] A. Oldfors, P. Sourander, D. L. Armstrong, A. K. Percy, I. Witt-Engerström and B. A. Hagberg, "Rett Syndrome: Cerebellar Pathology," Pediatric Neurology, Vol. 6, No. 5, pp. 310-314. doi:10.1016/0887-8994(90)90022-S

[16] T. J. Stradomska, A. Tylki-Szymańska and Z. Bentkowski, "Very Long-Chain Fatty Acids in Rett Syndrome," European Journal of Pediatrics, Vol. 158, No. 3, 1999, pp. 226-229. doi:10.1007/s004310051055

[17] L. Burd, R. Kemp, H. Knull and D. Loveless, "A Review of the Biochemical Pathways Studied and Abnormalities Reported in the Rett Syndrome," Brain \& Development, Vol. 12, No. 4, 1990, pp. 444-448. doi:10.1016/S0387-7604(12)80081-7

[18] P. Blardi, A. de Lalla, T. D’Ambrogio, M. Zappella, G. Cevenini, L. Ceccatelli, A. Auteri and J. Hayek, "Rett Syndrome and Plasma Leptin Levels," The Journal of Pediatrics, Vol. 150, No. 1, 2007, pp. 37-39. doi:10.1016/j.jpeds.2006.10.061

[19] P. Blardi, A. de Lalla, T. D'Ambrogio, G. Vonella, L. Ceccatelli, A. Auteri and J. Hayek, "Long-Term Plasma
Levels of Leptin and Adiponectin in Rett Syndrome," Clinical Endocrinology (Oxford), Vol. 70, No. 5, 2009, pp. 706-709. doi:10.1111/j.1365-2265.2008.03386.x

[20] K. J. Motil, R. Schultz, B. Brown, D. C. Glaze and A. K. Percy, "Altered Energy Balance May Account for Growth Failure in Rett Syndrome," Journal of Child Neurology, Vol. 9, No. 3, 1994, pp. 315-319. doi: $10.1177 / 088307389400900319$

[21] F. Carbone, C. La Rocca and G. Matarese, "Immunological Functions of Leptin and Adiponectin," Biochimie, Vol. 94, No. 10, 2012, pp. 2082-2088. doi:10.1016/j.biochi.2012.05.018

[22] C. Sticozzi, G. Belmonte, A. Pecorelli, F. Cervellati, S. Leoncini, C. Signorini, L. Ciccoli, C. De Felice, J. Hayek and G. Valacchi, "Scavenger Receptor B1 Post-Translational Modifications in Rett Syndrome," FEBS Letters, 2013 (in press). doi:10.1016/j.febslet.2013.05.042

[23] C. De Felice, C. Signorini, S. Leoncini, A. Pecorelli, T. Durand, G. Valacchi, L. Ciccoli and J. Hayek, "The Role of Oxidative Stress in Rett Syndrome: An Overview," Annals of the New York Academy of Sciences, Vol. 1259, 2012, pp. 121-135. doi:10.1111/j.1749-6632.2012.06611.x

[24] S. Leoncini, C. De Felice, C. Signorini, A. Pecorelli, T. Durand, G. Valacchi, L. Ciccoli and J. Hayek, "Oxidative Stress in Rett Syndrome: Natural History, Genotype, and Variants," Redox Report, Vol. 16, No. 4, 2011, pp. 145153. doi:10.1179/1351000211Y.0000000004

[25] C. Signorini, C. De Felice, S. Leoncini, A. Giardini, M. D'Esposito, S. Filosa, F. Della Ragione, M. Rossi, A. Pecorelli, G. Valacchi, L. Ciccoli and J. Hayek, "F $F_{4}$ Neuroprostanes Mediate Neurological Severity in Rett Syndrome," Clinica Chimica Acta, Vol. 412, No. 15-16, 2011, pp. 1399-1406. doi:10.1016/j.cca.2011.04.016

[26] C. De Felice, C. Signorini, T. Durand, C. Oger, A. Guy, V. Bultel-Poncé, J-M Galano, L. Ciccoli, S. Leoncini, M. D'Esposito, S. Filosa, A. Pecorelli, G. Valacchi and J. Hayek, "F 2 -Dihomo-Isoprostanes as Potential Early Biomarkers of Lipid Oxidative Damage in Rett Syndrome," Journal of Lipid Research, Vol. 52, No. 12, 2011, pp. 2287-2297. doi:10.1194/jlr.P017798

[27] C. Signorini, C. De Felice, T. Durand, C. Oger, J.-M. Galano, S. Leoncini, A. Pecorelli, G. Valacchi, L. Ciccoli and J. Hayek, "Isoprostanes and 4-Hydroxy-2-nonenal: Markers or Mediators of Disease? Focus on Rett Syndrome as a Model of Autism Spectrum Disorder," Oxidative Medicine and Cellular Longevity, 2013, Article ID: 343824. doi: $10.1155 / 2013 / 343824$

[28] J.-M. Galano, E. Mas, A. Barden, T. A. Mori, C. Signorini, C. De Felice, A. Barrett, C. Opere, E. Pinot, E. Schwedhelm, R. Benndorf, J. Roy, J. Y. Le Guennec, C. Oger and T. Durand, "Isoprostanes and Neuroprostanes: Total Synthesis, Biological Activity and Biomarkers of Oxidative Stress in Humans," Prostaglandins \& Other Lipid Mediators, 2013 (in press). doi:10.1016/j.prostaglandins.2013.04.003

[29] T. Durand, C. De Felice, C. Signorini, C. Oger, V. BultelPoncé, A. Guy, J.-M. Galano, S. Leoncini, L. Ciccoli, A. Pecorelli, G. Valacchi and J. Hayek, "F $F_{2}$-Dihomo-Iso- 
prostanes and Brain White Matter Damage in Stage 1 Rett Syndrome," Biochimie, Vol. 95, No. 1, 2013, pp. 86-90. doi:10.1016/i.biochi.2012.09.017

[30] C. De Felice, C. Signorini, T. Durand, L. Ciccoli, S. Leoncini, M. D'Esposito, S. Filosa, C. Oger, A. Guy, V. Bultel-Poncé, J.-M. Galano, A. Pecorelli, L. De Felice, G. Valacchi and J. Hayek, "Partial Rescue of Rett Syndrome by $\omega-3$ Polyunsaturated Fatty Acids (PUFAs) Oil," Genes \& Nutrition, Vol. 7, No. 3, 2012, pp. 447-458. doi:10.1007/s12263-012-0285-7

[31] C. N. Serhan, M. Arita, S. Hong and K. Gotlinger, "Resolvins, Docosatrienes, and Neuroprotectins, Novel Omega-3-Derived Mediators, and Their Endogenous Aspirin-Triggered Epimers," Lipids, Vol. 39, No. 11, 2004, pp. 1125-1132. doi:10.1007/s11745-004-1339-7

[32] C. N. Serhan, "Systems Approach with Inflammatory Exudates Uncovers Novel Anti-Inflammatory and ProResolving Mediators," Prostaglandins, Leukotrienes, and Essential Fatty Acids, Vol. 79, No. 3-5, 2008, pp. 157-
163. doi:10.1016/j.plefa.2008.09.012

[33] C. Arnold, M. Markovic, K. Blossey, G. Wallukat, R. Fischer, R. Dechend, A. Konkel, C. von Schacky, F. C. Luft, D. N. Muller, M. Rothe and W. H. Schunck, "Arachidonic Acid-Metabolizing Cytochrome P450 Enzymes Are Targets of 3 Fatty Acids," The Journal of Biological Chemistry, Vol. 285, No. 43, 2010, pp. 32720-32733. doi:10.1074/jbc.M110.118406

[34] C. M. Buchovecky, S. D. Turley, H. M. Brown, S. M. Kyle, J. G. McDonald, B. Liu, A. A. Pieper, W. Huang, D. M. Katz, D. W. Russell, J. Shendure and M. J. Justice, "A Suppressor Screen Mecp2 Mutant Mice Implicates Cholesterol Metabolism in Rett Syndrome," Nature Genetics, 2013 (in press). doi:10.1038/ng.2714

[35] M. Ewang-Emukowhate and A. S. Wierzbicki "LipidLowering Agents," The Journal of Cardiovascular Pharmacology and Therapeutics, 2013 (in press). doi:10.1177/1074248413492906 